\title{
Eliminating early childhood caries
}

\author{
By Claire Stevens CBE, Consultant in Paediatric Dentistry at Manchester University NHS Foundation Trust and media \\ spokesperson for and past President of the British Society of Paediatric Dentistry.
}

A mbitious targets and collaboration are the way forward if we are to eliminate early childhood caries. We know that $12 \%$ of three-year-old children exhibit visible dental decay. ${ }^{1}$

With so many pre-school children affected by caries, parents need to be hearing key prevention messages as soon as their child is born, if not earlier.

This is not a hopeless situation. By raising awareness and instilling good oral healthcare habits, we can help children develop good oral health behaviours they will maintain throughout their lives.

As practitioners, it is far better to have the opportunity to support a family before decay occurs, and to keep their children caries-free rather than having to manage caries and pain, often on an urgent basis. Prevention focused dental practices are highly successful, and where early access is possible, we have a real chance to raise a generation free of dental decay.

There are efforts and initiatives underway to achieve this. Greater Manchester Health and Social Care Partnership recently launched a $£ 1.5$ million regional programme of prevention, which will fund evidence-based prevention measures in four priority areas:

- Working with health visitors to distribute brushing packs and oral health messaging at six months and two and a half years

- Establishing supervised brushing in all early years settings

- Dental Check by One initiative

- Increasing fluoride varnish applications.

The hope is that we will start to see an improvement in the oral health of our young children, and in turn, a reduced demand on general anaesthetic services in the area.

It is our ambition to extend the scheme so that all children in Greater Manchester can benefit from these measures. Making a targeted effort with the young is not just the right thing to do, but in the long-term it should also bring considerable efficiency savings - it's very much a win-win situation.

The Dental Check by One (DCby1) campaign was launched by the British Society of Paediatric Dentistry in September 2017. It raises awareness among parents that they should take babies to see a dentist once their first teeth come through and before their first birthday.

Just six months after the launch, half of those surveyed by Mumsnet were aware of the importance of taking their children to a dentist within their first year. ${ }^{2}$ We now have 21 organisational supporters, industry partners and high profile ambassadors.

Improving children's oral health is not purely a matter of awareness and education. The reality is that resources are needed. Children and young people under the age of 18 - or 19 if in fulltime education - are entitled to free dental care through the NHS, yet many parents still encounter difficulty registering with a dentist.

The NHS Long Term Plan has recently been published. It is an important document and outlines the direction of travel for the NHS, but does not go far enough.

The Long Term Plan contains welcome references to children's oral health, including mention of the 13 Starting Well areas, as well as a strong focus on prevention and the need for digital innovation. While this is a real achievement, the profession should build on this momentum to continue to campaign for improvements in children's oral health. Ideally, more areas will introduce Starting Well, but this will require collaborative work from dentists, commissioners and local government.

Setting ambitious targets is important. The Commissioning Standard for Paediatric Dentistry was published nearly a year ago and is already making a difference. Currently we simply do not have the workforce in place to deliver the quality of dental care for children we should aspire to.

There is a pressing need to train greater numbers of specialists in paediatric dentistry, and to re-evaluate the skill mix of our existing teams. Work is underway to determine the accreditation process for Level 2 practitioners and many areas have completed an oral health needs assessment so that they can accurately plan services to meet the needs of their local populations.

Improving paediatric dental care and the initiatives to support this are key topics, with a wealth of information to discuss far beyond the confines of this article. Real headway is being made towards improving the oral health care of children, but sustained efforts are required.

If this article has intrigued you, you may wish to attend my forthcoming lecture at the British Dental Conference and Dentistry Show, where I will be expanding upon this vital work.

I will also share details about a scheme called Mini Mouthcare Matters, led by BDSD's Dr Urshla Devalia. This is the children's equivalent of Mouthcare Matters; a programme set up to improve the oral health of older patients in hospitals and residential care.

We have a real chance of consigning tooth decay to the history books and that's the target we are aiming for. There are effective, evidence-based means to improve preventative care.

The British Dental Conference and Dentistry Show 2019 will be held on 17 and 18 May 2019 at the Birmingham NEC, co-located with the Dental Technology Showcase.

More information is available at www.thedentistryshow.co.uk or by calling 02073485270 or emailing dentistry@closerstillmedia.com.

\section{References}

1. Public Health England. Dental public health epidemiology programme: oral health survey of three-year-old children 2013. 2014.

2. Bissett J. Mumsnet survey reveals $50 \%$ of parents aware of first birthday dental visit. Dental Nursing, 2018. Available at https://www.dental-nursing.co.uk/news/ mumsnet-survey-reveals-1-in-4-failing-to-access-nhsdental-care (accessed April 2019). 